\title{
BMJ Open Transcultural adaptation and psychometric evaluation of the mainland China version of Nursing Home Survey on Patient Safety Culture Questionnaire: a cross-sectional survey based on 50 nursing homes in China
}

To cite: Li Y, Cheng Y, Hu X, et al. Transcultural adaptation and psychometric evaluation of the mainland China version of Nursing Home Survey on Patient Safety Culture Questionnaire: a cross-sectional survey based on 50 nursing homes in China. BMJ Open 2021;11:e043994. doi:10.1136/ bmjopen-2020-043994

- Prepublication history and additional supplemental material for this paper are available online. To view these files, please visit the journal online (http://dx.doi.org/10.1136/ bmjopen-2020-043994).

Received 21 August 2020 Accepted 09 June 2021

Check for updates

(c) Author(s) (or their employer(s)) 2021. Re-use permitted under CC BY-NC. No commercial re-use. See rights and permissions. Published by BMJ.

For numbered affiliations see end of article.

\section{Correspondence to}

Professor Xiuying Hu; xiuyinghuhl@gmail.com and Mr Longhao Zhang; zhanglongha01990@hotmail. com

\section{ABSTRACT}

Objective To provide a validated Chinese-language measurement of the Nursing Home Survey on Patient Safety Culture (NHSOPS) in mainland China. The primary goal is to carry out a transcultural adaptation of the NHSOPS Questionnaire into Chinese and evaluate its psychometric properties.

Design A psychometric evaluation study is constructed. First, the 'translation-back-translation-cultural adaptation' and the pretesting procedure were followed to introduce the NHSOPS. Second, a cross-sectional survey was used to assess the psychometric properties for the mainland China version of the NHSOPS (M-NHSOPS), and a testretest survey was then applied.

Setting and participants The survey was carried out among 1397 nursing home staff from 50 nursing homes in Southwest China.

Outcome measures Exploratory factor analysis (EFA) was used to assess the potential structure, and confirmatory factor analysis (CFA) was then applied. Reliability was assessed by the content validity index, Cronbach's $\alpha$ and the test-retest value.

Results Among the 1397 respondents, 1211 were included (86.7\%). EFA was used, and a nine-factor structure was explored. Five factors (Cronbach's $\alpha>0.6$ ) were selected into the new structure for the M-NHSOPS. Moreover, data showed that it was suitable for CFA, and convergent validity and discriminant validity were satisfactory. On the other hand, M-NHSOPS contains five dimensions and 22 items. The overall Cronbach's $\alpha$ value was 0.883 ; the values of each dimension ranged from 0.648 to 0.913 . Additionally, content validity showed significant performance. Eventually, testretest reliability was 0.892 , and each dimension was 0.713 , $0.809,0.924,0.795$ and 0.859 , respectively $(p<0.001)$. Conclusions M-NHSOPS has acceptable reliability and satisfactory validity among staff of nursing homes in Southwest China, and further verification among samples in other regions of mainland China is required.

\section{INTRODUCTION}

Preventing incidents such as medication errors and misconducts are of paramount
Strengths and limitations of this study

Well-applied translation and cultural adaptation process.

- Clarified inclusion criteria for different staff of the scale.

- Relatively abundant sample size.

- Further verification among samples in other regions of mainland China is required.

- Further explorations of patient safety culture connotations in nursing homes in mainland China are recommended.

importance in elderly care institutions, ${ }^{1}$ and patient safety culture (PSC) refers to the prevailing attitudes, beliefs, values and behaviours of employees formed by health institutions to achieve the goal of patient safety. ${ }^{2}$ The inverse association between PSC and adverse event occurrence was proved. ${ }^{3}$ Thus, PSC has been accepted as an essential quality indicator across all healthcare settings. ${ }^{4}$ For improvement, the most common approach has been to develop or introduce reliable PSC assessment tools in specific countries and then conduct crosssectional surveys in organisations.

As mentioned above, assessing the current situation and identifying the weak aspects of organisations are regarded as the most challenging procedures. ${ }^{5}$ Correspondingly, a reliable tool is a prerequisite for reliable assessment. On one hand, up to now, research on the evaluation of PSC has largely been confined to hospitals. ${ }^{6}$ Numerous tools such as Safety Attitudes Questionnaire (SAQ) and Hospital Survey on Patient Safety Culture (HSOPS) were developed. SAQ and HSOPS have been widely introduced, such as 
in Norway, ${ }^{78}$ Greece $^{9}$ and China ${ }^{1011}$. On the other hand, some pieces of evidence showed that nursing homes (NHs) are at high risk. ${ }^{12}$ Residents in NHs have multiple health problems and require advanced medications. Some of them even have cognitive impairments, which leads to increased potential risks. ${ }^{13}$ However, previous research for PSC on NHs has been lacking. ${ }^{4}$

Despite increased advocacy of use of PSC in NHs in recent years, efforts in evaluating $\mathrm{PSC}$ in $\mathrm{NHs}$, primarily available tools, are still lacking. ${ }^{12}$ In 2008, the Agency for Healthcare Research and Quality (AHRQ) developed a specific tool-Nursing Home Survey on Patient Safety Culture (NHSOPS) for $\mathrm{NHs},{ }^{14}$ which had previously developed HSOPS. Subsequently, NHSOPS has also been validated into different regions and cultures, including Norway, ${ }^{15}$ France, ${ }^{16}$ Switzerland ${ }^{17}$ and Spain ${ }^{18}$. In mainland China, NHs are categorised by the government into three types: NHs hosted and managed by government party (named as type $\mathrm{A}$ in this research), hosted by the government but managed by the non-government party (type B) and hosted and managed by the non-government party (type C).$^{19}$ Research suggests that the governmentowned nursing homes still enjoy more benefits than private organisations in staffing, funding and insurance. ${ }^{20}$ However, at the same time $\mathrm{NHs}$ are still occasionally associated with safety risks. The Chinese $\mathrm{NH}$ industry is under initial development, and the quality varies among different NHs in comparison with developed countries. ${ }^{21}$

Recently, two Chinese versions of NHSOPS were reported in 2016 and 2017. ${ }^{12}{ }^{22}$ For Xiao's ${ }^{22}$ version in mainland China, the sample size was insufficient $(n=322)$, and it lacked consideration of staff classification, content of scale and applicability of certain items. Furthermore, there are numerous differences between mainland China and Taiwan versions including ${ }^{12}$ dialects, subcultures, functions, classifications of NHs, types of professionals in NHs, staffing proportions of professionals in different kinds of NHs and different development levels of NHs. ${ }^{23-25}$ Accordingly, NHs in mainland China are still in urgent need of a reliable and validated Chinese version of an assessment tool to evaluate their psychometric properties to have baseline data on the PSC of NHs in mainland China.

In this study, we focus on the intercultural adaptation of NHSOPS into the mainland based on data from $50 \mathrm{NHs}$ in Southwest China and evaluation of its psychometric properties.

\section{METHODS}

The NHSOPS contains 42 items focused on 12 dimensions: teamwork, staffing, compliance with procedures, training and skills, non-punitive response to mistakes, handoffs, feedback and communication about incidents, communication openness, supervisor expectations and actions promoting resident safety, overall perceptions of resident safety, management support for resident safety and organisational learning. ${ }^{14}$ Two overall rating questions are at the end of the scale. The total score ranges from 0 to 210; the higher scores represent a superior safety culture in the organisation. Copyright of the original scale (utilisation and translation) was attained in October 2015 from the AHRQ.

This study was conducted in two phases: an initial phase involving the translation and cultural adaptation of the questionnaire and a second phase in which the psychometric properties of the questionnaire were evaluated.

\section{Translation and transcultural adaptation of NHSOPS in mainland China}

A cross-cultural adaptation procedure was conducted: translation, back-translation, cultural adjustment and pretesting. The first stage was to translate the original scale into Chinese by two independent native postgraduates with fluency in English. Both graduates majored in nursing and had sufficient understandings on PSC. In the second stage, a professor from evidence-based medicine who had been focusing on the research of PSC synthesised the two Chinese versions into one. Two bilingual translators with no medical backgrounds then translated it back to Chinese separately. Both of them were blind to the questionnaire. A geriatric nursing professor examined the equivalence of context and semantics by comparing the back-translated versions with the original one and checking if it was translated accordingly.

The cultural adaptation process included three parts, with three rounds of group meetings, two rounds of expert consultations and a pilot test. It is recommended by the User's Guide developed by AHRQ for international translators that group meetings focused on translation and adjustment should be used to make a superior cultural adaptation. ${ }^{14}$ The research team members included three $\mathrm{PhD}$ students, four master's students in geriatric nursing and two master's students in evidencebased medicine. The criteria for inclusion of experts were (1) having relevant experience of safety culture, elderly care, elderly patient management, hospital management, NH management or public health; (2) with more than 10 years of relevant experience; and (3) informed consent. Nineteen experts participated in two rounds of consultations, and all were from the Sichuan Province of China. Their age ranged from 40 to 60 , and only one expert was above 60 ; three $(15.8 \%)$ of them have worked for $10-19$ years, four $(21.1 \%)$ for 20-29 years and 12 $(63.3 \%)$ for over 30 years; three $(15.8 \%)$ of them graduated from junior college, nine $(47.4 \%)$ were undergraduates, four $(21.1 \%)$ have master's degrees and three $(15.8 \%)$ have doctoral degrees; seven $(36.8 \%)$ of them were head nurses in hospitals, three $(15.8 \%)$ were deputy head nurse in hospitals, one $(5.3 \%)$ was in the management layer of the nursing department in a hospital, three $(15.8 \%)$ were from Sichuan Association of Senior Services, three $(15.8 \%)$ were in the management laver of $\mathrm{NHs}$, one $(5.3 \%)$ was a professor of nursing and one $(5.3 \%)$ was a professor of statistics. Eventually, a pilot test was conducted by querying 200 care providers in $\mathrm{NHs}$ 


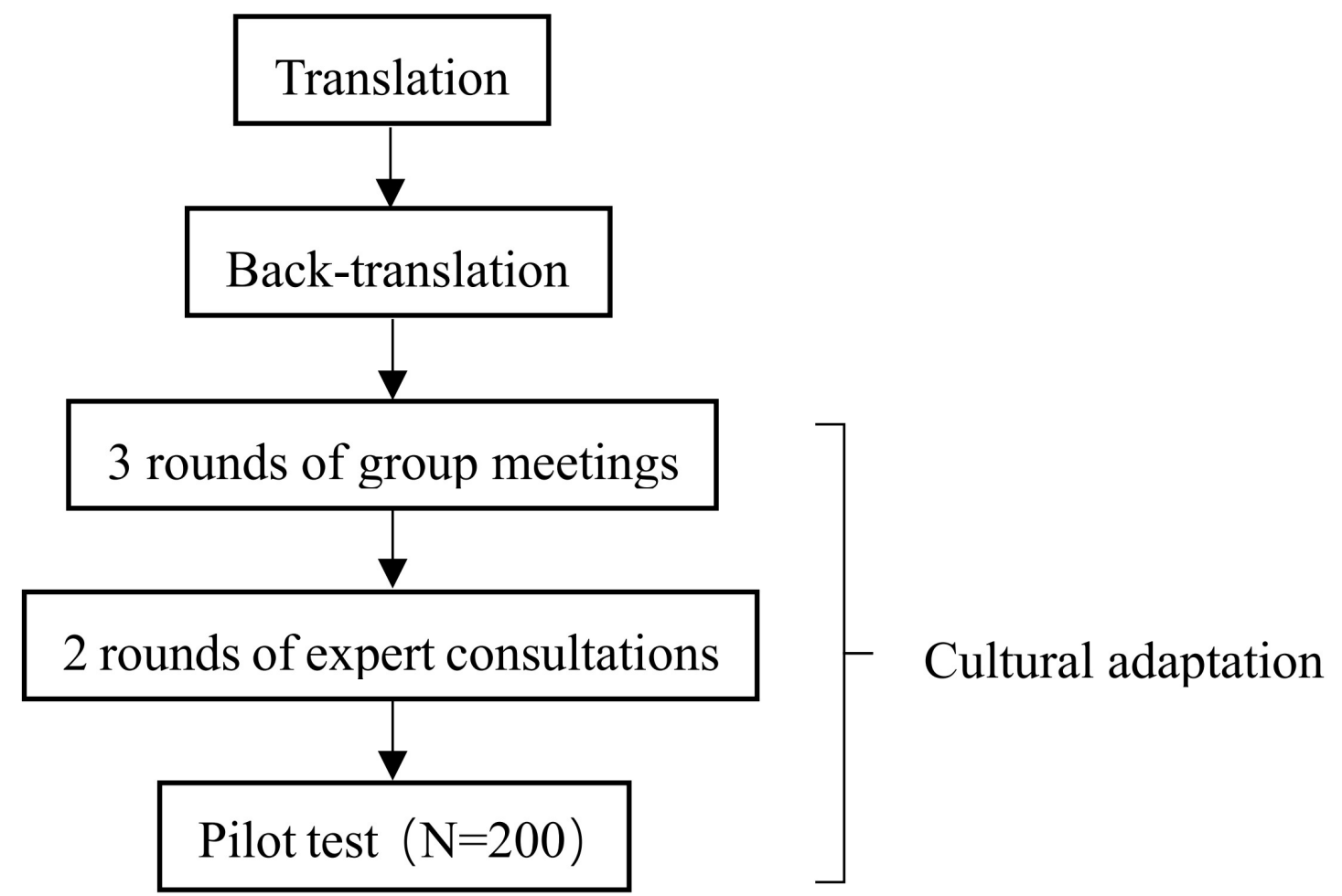

Figure 1 Translation and cultural adaptation process.

to complete the survey (three NHs in Xindu District of Sichuan Province), and no difficulty in understanding or responding was reported. The translation and adaptation process is shown in figure 1.

\section{Psychometric validation of mainland China version of the} NHSOPS (M-NHSOPS)

This cross-sectional study was conducted in Sichuan Province, Southwest China, from 2016 to 2017. Initially, we contacted three $\mathrm{NHs}$ and pilot-tested a subgroup $(n=200)$. Based on the research information, we then accessed each type of $\mathrm{NH}$ (A, B and C) from 20 administrative regions. Theoretically, at least one type of $\mathrm{NH}(\mathrm{A}$, B and C) should be extracted for each area.

In this study, $50 \mathrm{NHs}$ were enrolled, and 1397 staff were invited. Inclusion criteria were (1) personnel who provide direct care service to the elderly in NHs, (2) working full time and (3) informed consent and voluntary participation. Exclusion criteria were (1) staff who are absent or leaving the NH and (2) internship or trainee. Questionnaires were distributed by the research team and checked immediately after completion by respondents. In case of failed completion for certain items, members of the research team would remind them for completion. Questionnaires were excluded if their missing value is $>20 \%$ from this survey. To evaluate test-retest reliability, a subgroup $(n=30)$ completed the survey twice on day 0 as well as on day 14 . This study was approved by the institutional review board of the West China Hospital, Chengdu, China.

\section{Statistical analysis}

Data were analysed by SPSS V.24.0 and AMOS V.19.0, and $p<0.05$ was considered statistically significant in twotailed tests. The general characteristics of our volunteer $\mathrm{NHs}$ and respondent staff were described by means (SD) or frequencies of categorical items.

Expert consultations were analysed by the recovery rate and content validity index (CVI). This measurement includes item-level I-CVI and scale-level S-CVI. The S-CVI at the scale level also includes average S-CVI (S-CVI/Ave) and universal agreement S-CVI (S-CVI/UA). Exploratory factor analysis (EFA) was applied to explore the potential structure. In EFA, the Kaiser-Meyer-Olkin (KMO) value, Bartlett's $\chi^{2}$ value, $\mathrm{df}$ value, the value of variance, eigenvalues and factor loading were calculated to indicate the properties of the new model. A further factor structure was developed with factors whose Cronbach's $\alpha$ is $>0.6$. The confirmatory factor analysis (CFA) was used to test if this factor structure was suitable and, at the same time, convergent validity and discriminant validity were explored. Pearson correlation coefficient was used to calculate the retest reliability. Cronbach's $\alpha$ coefficient was used to assess the reliability of the scale.

\section{Inclusion criteria of items and dimensions of the M-NHSOPS} In this study, EFA was first applied to explore the original structure of the data set, and a preliminary factor structure was obtained, and the validity of each factor was explored. Factors whose Cronbach's $\alpha$ is $>0.6$ and item loading is $>0.5$ were then selected as the new structure for M-NHSOPS. 
Table 1 Characteristics of the nursing homes $(\mathrm{NHs})(n=50)$

\section{Type A}

(no. of Type B (no. Type C (no.

$\mathrm{NHs} /$ no. of NHs/no. of NHs/no. of Total of

\begin{tabular}{lllll} 
Areas & of staff) & of staff) & staff) & staff \\
\hline Qing Yang & $1 / 70$ & $1 / 40$ & $1 / 10$ & 120 \\
\hline Cheng Hua & $1 / 24$ & - & $2 /(14 / 17)$ & 55 \\
\hline Jin Jiang & - & - & $2 /(19 / 13)$ & 32 \\
\hline Jin Niu & - & $1 / 19$ & $1 / 29$ & 48 \\
\hline Wu Hou & - & - & $1 / 17$ & 17 \\
\hline Gao Xin & $1 / 23$ & - & - & 23 \\
\hline Du Jiangyan & $1 / 57$ & - & $2 /(12 / 10)$ & 79 \\
\hline Shuang Liu & $1 / 7$ & $1 / 40$ & $1 / 20$ & 67 \\
\hline Long Quan & $1 / 51$ & $1 / 44$ & $1 / 39$ & 134 \\
\hline Xin Du & $1 / 130$ & $1 / 68$ & $1 / 26$ & 224 \\
\hline Pi Du & $1 / 10$ & - & $2 /(36 / 24)$ & 70 \\
\hline Peng Zhou & $1 / 17$ & - & $1 / 9$ & 26 \\
Chong Zhou & $1 / 9$ & - & $1 / 12$ & 21 \\
\hline Da Yi & $1 / 48$ & $1 / 8$ & $1 / 11$ & 67 \\
\hline Qiong Lai & $1 / 8$ & $1 / 8$ & $1 / 10$ & 26 \\
\hline Pu Jiang & $1 / 5$ & $1 / 12$ & - & 17 \\
\hline Xin Jin & $1 / 9$ & $1 / 17$ & $1 / 9$ & 35 \\
\hline Jin Tang & $1 / 12$ & $1 / 12$ & - & 24 \\
\hline Qing Baijiang & $1 / 9$ & $1 / 26$ & $1 / 6$ & 41 \\
\hline Wen Jiang & $1 / 27$ & $1 / 17$ & $1 / 30$ & 74 \\
\hline
\end{tabular}

\section{RESULTS}

\section{Translation and transcultural adaptation}

The M-NHSOPS contains five dimensions and 22 items. The original dimensions 'staffing' (A3, A8, A16 and A17), 'training and skills' (A7, A11 and A13), 'nonpunitive response to mistakes' (A10, A12, A15 and A18) and 'communication openness' (B7, B9 and B11) were deleted from M-NHSOPS. Items such as A4, A9, B4, B5, B8, C1, C2 and D3 were also deleted. The M-NHSOPS Scale retains the 5-response Likert Scale and 'Does Not Apply or Don't Know' options as well as two overall evaluation items. Further details are shown in online supplemental appendices 1 and 2.

Of the 1397 questionnaires distributed, 186 questionnaires were excluded since over $20 \%$ of items were missing, resulting in a total of 1211 responses $(86.7 \%$ response rate).

\section{Characteristics of enrolled NHs and participants}

Among the 20 administrative areas, nine have all types of NHs, eight have two types that contain at least a type A or a type B NH and three areas have only one kind of NH in which two regions have only type $\mathrm{C}$ NHs. The respondents from these facilities ranged from 17 to 224. Additional details are shown in table 1.

Most staff were from type A NHs (42.6\%), and 77.3\% of them were women. The age ranged from 18 to 80 $(42.05 \pm 13.04)$, and those between 46 and 60 comprised
Table 2 Characteristics of the respondents $(n=1211)$

Characteristics N (\%)

Type of facility

$\begin{array}{ll}\text { A } & 516(42.6 \%) \\ \text { B } & 322(26.6 \%) \\ \text { C } & 373(30.8 \%)\end{array}$

Sex

Man $275(22.7 \%)$

Woman $936(77.3 \%)$

Age (years)

$\begin{array}{ll}18-40 & 497(41.0 \%) \\ 40-60 & 572(47.3 \%) \\ 60-80 & 142(11.7 \%)\end{array}$

Education

\begin{tabular}{ll}
\hline Illiteracy & $73(6.0 \%)$ \\
\hline Primary school & $201(16.6 \%)$ \\
\hline Middle school & $320(26.4 \%)$ \\
\hline High school & $95(7.8 \%)$ \\
\hline Technical secondary school & $72(5.9 \%)$ \\
\hline Junior college & $253(20.9 \%)$ \\
\hline Undergraduate & $176(14.5 \%)$ \\
\hline Master's degree and above & $21(1.7 \%)$ \\
\hline Position & \\
\hline Management layer & $198(16.4 \%)$ \\
\hline Doctor & $138(11.4 \%)$ \\
\hline Nurse & $186(15.4 \%)$ \\
\hline Nursing assistant & $659(54.4 \%)$ \\
\hline Others & $30(2.5 \%)$ \\
\hline Professional licenses & \\
\hline Paramedical staff & \\
\hline Yes & $271(22.4 \%)$ \\
\hline No & $940(77.6 \%)$ \\
\hline Elderly care assistant staff & \\
\hline Yes & $357(29.5 \%)$ \\
\hline No & $854(70.5 \%)$ \\
\hline Number of years in nursing home & \\
\hline$<1$ year & $147(12.1 \%)$ \\
\hline$\geq 1$ year & $1064(87.9 \%)$ \\
\hline Working hours per week & \\
\hline$<40$ hours & $107(8.8 \%)$ \\
\hline$\geq 40$ hour & $1104(91.2 \%)$ \\
\hline
\end{tabular}

the majority. Merely $14.5 \%$ of them were undergraduates, and $1.7 \%$ of them had acquired a master's degree. Nursing assistant (54.4\%) was the most prominent composition in NHs. Additional details were shown in table 2. 
Table 3 Factors and item loadings explored by exploratory factor analysis

\begin{tabular}{|c|c|c|}
\hline Factor number & Items included & Item loadings \\
\hline \multirow[t]{10}{*}{1} & D6 & 0.808 \\
\hline & D5 & 0.774 \\
\hline & D8 & 0.770 \\
\hline & D9 & 0.755 \\
\hline & D10 & 0.734 \\
\hline & D1 & 0.727 \\
\hline & D7 & 0.703 \\
\hline & C3 & 0.644 \\
\hline & D4 & 0.603 \\
\hline & D2 & 0.569 \\
\hline \multirow[t]{5}{*}{2} & B3 & 0.801 \\
\hline & B1 & 0.779 \\
\hline & B2 & 0.776 \\
\hline & B10 & 0.680 \\
\hline & B6 & 0.513 \\
\hline \multirow[t]{3}{*}{3} & $\mathrm{~A} 2$ & 0.844 \\
\hline & $\mathrm{A} 1$ & 0.838 \\
\hline & A5 & 0.690 \\
\hline \multirow[t]{3}{*}{4} & A11 & 0.699 \\
\hline & $\mathrm{A} 7$ & 0.653 \\
\hline & A9 & 0.505 \\
\hline \multirow[t]{2}{*}{5} & B5 & 0.840 \\
\hline & B8 & 0.815 \\
\hline \multirow[t]{2}{*}{6} & A6 & 0.761 \\
\hline & A14 & 0.693 \\
\hline \multirow[t]{2}{*}{7} & A18 & 0.658 \\
\hline & C1 & 0.541 \\
\hline \multirow[t]{2}{*}{8} & B9 & 0.703 \\
\hline & A17 & 0.566 \\
\hline \multirow[t]{2}{*}{9} & A10 & 0.766 \\
\hline & A8 & 0.626 \\
\hline
\end{tabular}

\section{VALIDITY}

\section{Structural validity}

To explore the most suitable factor structure of the scale, we applied EFA. Principal component analysis and the maximum variance method were used. Factors with eigenvalues above one were selected, while items with the maximum factor loading value $<0.5$ and those with double loading were deleted. The KMO value was 0.928 , and Bartlett's test of sphericity was significant $\left(\chi^{2}=20882.645\right.$, df value was 861 and $\mathrm{p}<0.001$ ), and it accounted for $58.096 \%$ of the variance. As a result, nine factors were precipitated. Additional details are shown in table 3.

Based on EFA, a new five-factor structure was formed, of which all factors' Cronbach's $\alpha$ was above 0.6. To test the new structure, CFA was used for which Chi-square/ df $\quad(\mathrm{CMIN} / \mathrm{df})=2.631$, root mean square residual $(\mathrm{RMR})=0.026, \quad$ goodness-of-fit $\quad$ index $\quad(\mathrm{GFI})=0.967$, adjusted goodness-of-fit index (AGFI) $=0.952$, normed fit index $(\mathrm{NFI})=0.965$, relative fit index $(\mathrm{RFI})=0.955$, incremental fit index (IFI) $=0.978$, Tucker - Lewis index $(\mathrm{TLI})=0.971$, comparative fit index $(\mathrm{CFI})=0.978$ and root mean square error of approximation $($ RMSEA $)=0.037$. All items were identified to have a five-dimensional construct with 22 items. Additional details are displayed in tables 4 and 5 , respectively.

\section{RELIABILITY}

Expert consultation related indicators and content reliability

Two rounds of expert consultations were used to localise the scale, and recovery rates of two rounds were $100 \%$. The CVI was used to assess the fitness between the content to be measured and the content measured. In this study, except for A6 and B10 (both I-CVI values were 94.7\%), all values of remaining items were $100 \%$. The S-CVI/UA was $95.2 \%$, and S-CVI/Ave was $99.4 \%$.

\section{Reliability analysis}

Values of reliability were calculated on the nine factors extracted by EFA, and Cronbach's $\alpha$ ranged from 0.366 to 0.913 . The overall Cronbach's $\alpha$ value of the mainland China version scale was 0.883 . Additional details are displayed in table 6 .

\section{Test-retest reliability}

The Pearson correlation coefficient was applied to calculate test-retest reliability. We retested 30 employees in a $\mathrm{NH}$ after a $0-14$ interval. The test-retest reliability was 0.892 , in which each dimension was $0.713,0.809,0.924$, 0.795 and $0.859(\mathrm{p}<0.001)$.

\section{DISCUSSION}

In the translation period, there were 42 items, which was similar to Xiao's study, ${ }^{22}$ Taiwan and China versions, ${ }^{12}$ and French version, ${ }^{16}$ compared with the Norwegian version with 43 items ${ }^{15}$ in which it split item B3, "we have all the information we need when residents are transferred from hospital', into two items. Quality of translation and cultural adaptation were guaranteed by translation, backtranslation and cultural adaptation process. Additionally, we used data from the expert consultations to explore content validity. The recovery rates of two rounds were high, indicating the active participation of experts in this study. All I-CVI data were higher than 0.78 for three and more experts. ${ }^{26}$ The values of S-CVI/UA and S-CVI/Ave were $\geq 0.8$ and $\geq 0.9$, respectively, indicating exceptional levels. ${ }^{27}$ All indicators above showed that the M-NHSOPS has satisfactory content validity.

The recovery rate was significantly higher than the French version of $58.4 \%,{ }^{16}$ the Norwegian version of $69 \%^{15}$ and the Swiss version of $66 \%{ }^{17}$ However, it was lower than Xiao's study of $92.3 \%^{22}$ and the Taiwan and 


\begin{tabular}{|c|c|c|c|c|c|c|}
\hline Factor no. & Items & Factor loading & $\begin{array}{l}\text { Reliability } \\
\text { coefficient }\end{array}$ & Measuring error & $\begin{array}{l}\text { Composite } \\
\text { reliability }\end{array}$ & $\begin{array}{l}\text { Average variance } \\
\text { extracted }\end{array}$ \\
\hline \multirow[t]{10}{*}{1} & D1 & 0.724 & 0.524 & 0.476 & 0.917 & 0.527 \\
\hline & D2 & 0.588 & 0.346 & 0.654 & & \\
\hline & C3 & 0.661 & 0.437 & 0.563 & & \\
\hline & D4 & 0.614 & 0.377 & 0.623 & & \\
\hline & D5 & 0.792 & 0.627 & 0.373 & & \\
\hline & D6 & 0.826 & 0.682 & 0.318 & & \\
\hline & D7 & 0.703 & 0.494 & 0.506 & & \\
\hline & D8 & 0.785 & 0.616 & 0.384 & & \\
\hline & D9 & 0.792 & 0.627 & 0.373 & & \\
\hline & D10 & 0.733 & 0.537 & 0.463 & & \\
\hline \multirow[t]{5}{*}{2} & B1 & 0.772 & 0.596 & 0.404 & 0.854 & 0.543 \\
\hline & B2 & 0.829 & 0.687 & 0.313 & & \\
\hline & B3 & 0.795 & 0.632 & 0.368 & & \\
\hline & B6 & 0.577 & 0.333 & 0.667 & & \\
\hline & B10 & 0.685 & 0.469 & 0.531 & & \\
\hline \multirow[t]{3}{*}{3} & $\mathrm{~A} 1$ & 0.867 & 0.752 & 0.248 & 0.826 & 0.621 \\
\hline & A2 & 0.887 & 0.787 & 0.213 & & \\
\hline & A5 & 0.570 & 0.325 & 0.675 & & \\
\hline \multirow[t]{2}{*}{5} & B5 & 0.815 & 0.664 & 0.336 & 0.855 & 0.748 \\
\hline & B8 & 0.912 & 0.832 & 0.168 & & \\
\hline \multirow[t]{2}{*}{6} & $A 6$ & 0.658 & 0.433 & 0.567 & 0.658 & 0.491 \\
\hline & A14 & 0.741 & 0.549 & 0.451 & & \\
\hline
\end{tabular}

China versions of $100 \%{ }^{12}$ The recovery rate in this study is relatively satisfactory. In this study, the average age of participants was $(42.05 \pm 13.04)$, and staff aged from 60 to 80 accounted for $11.7 \%$, while in the French version, ${ }^{16}$ only $7.2 \%$ of respondents were aged above 56 . In Taiwan and China versions, the average age was $(37.7 \pm 10.5) .{ }^{12}$ This result emphasises that respondents in this survey are considerably senior than those in other studies. Illiteracy accounted for $6.0 \%$, and staff whose educational background ranged from primary to high school comprised $50.9 \%$. However, in Taiwan and China versions, ${ }^{12}$ there was no illiterate staff, and individuals who have graduated from elementary to high schools were $36.6 \%$, and those who have diplomas and bachelor or higher degrees were $62.4 \%$. In brief, staff in Chinese NHs were lower educated than those in other studies. ${ }^{28}$ Additionally,

\begin{tabular}{|c|c|c|c|c|c|}
\hline Factor number & 1 & 2 & 3 & 5 & 6 \\
\hline 1 & 0.527 & & & & \\
\hline 2 & 0.375 & 0.543 & & & \\
\hline 3 & 0.180 & 0.082 & 0.621 & & \\
\hline 5 & 0.073 & 0.158 & 0.019 & 0.748 & \\
\hline 6 & 0.080 & 0.156 & 0.023 & 0.009 & 0.491 \\
\hline
\end{tabular}

staff who worked in NHs for less than a year comprised $12.1 \%$, while in Cappelen's study, it was $6.3 \% .{ }^{15}$ Staff who worked at least 40 hours/week comprised $91.2 \%$, while in Cappelen' s study, those who worked at least 35.5 hours/ week comprised $16.1 \%$. These indicate that staff in this study have less working experience while experience greater overtime than in other regions.

EFA explored a nine-factor structure with 31 items included. The value of KMO indicates sufficient

\begin{tabular}{llll}
\hline Table 6 & \multicolumn{3}{l}{ Cronbach's $\alpha$ values of the nine factors } \\
\hline $\begin{array}{l}\text { Factor } \\
\text { number }\end{array}$ & Included items & $\begin{array}{l}\text { Number } \\
\text { of items }\end{array}$ & Cronbach's $\alpha$ \\
\hline 1 & $\begin{array}{l}\text { D1/D2/C3/D4/D5/ } \\
\text { D6/D7/D8/D9/D10 }\end{array}$ & 10 & $0.913^{*}$ \\
\hline 2 & B1/B2/B3/B6/B10 & 5 & $0.851^{*}$ \\
\hline 3 & A1/A2/A5 & 3 & $0.797^{*}$ \\
\hline 4 & A7/A9/A11 & 3 & 0.565 \\
5 & B5/B8 & 2 & $0.851^{*}$ \\
\hline 6 & A6/A14 & 2 & $0.648^{*}$ \\
7 & A18/C1 & 2 & 0.393 \\
8 & B9/A17 & 2 & 0.422 \\
\hline 9 & A8/A10 & 2 & 0.366 \\
\hline${ }^{*}$ Cronbach's $\alpha>0.6$ & & & \\
\hline
\end{tabular}


intercorrelations, and the value of Bartlett's test of sphericity demonstrates that the data were ideal for factor analysis. Moreover, the cumulative contribution rate of this study that was over $40 \%$ indicates satisfactory construct validity. Comparing the nine-factor structure with the original US scale, four original dimensions (nine items) were deleted (staffing, non-punitive response to mistakes, communication openness and training and skills). The deletion of 'staffing' may be due to the proportion of staffing and the educational background of employees, for which $54.4 \%$ of the respondents were nursing assistants and $62.8 \%$ received lower education than secondary/high school. In brief, the majority of them have less/no staffing or management-relevant knowledge/experience, and the concept of workplace competition has not appeared to be instilled, ${ }^{29}$ which prevents them from participating in the staffing/management of the NH. Besides, due to the general management culture in China, there exists strict leadership hierarchy between superiors and subordinates in which management layers tend to be exclusively in charge of such kind of staffing matters, ${ }^{30}$ and most employees perceive themselves not being in the position to intervene with the upper management. The removal of 'non-punitive response to mistakes' and 'communication openness' may be related to the fact that the 'learn from error' climate and 'open communication' have not been well developed in domestic organisations. ${ }^{31}$ The original dimension 'training and skills' was deleted, which indicates that most staff in NHs have received little training in elderly care. China is in urgent demand of good-quality and well-structured training schemes for all types of staff. $^{32}$ To check the performance of the new five-factor structure of M-NHSOPS, CFA was applied. All values of GFI, AGFI, NFI, RFI, IFI, TFI and CFI were above $0.9,{ }^{33}$ while CMIN/df was less than 3, RMSEA was less than 0.08 and RMR was less than $0.05,{ }^{34}$ which indicates the fivefactor structure fits excellently. All values of composite reliability (CR) of the five dimensions were higher than 0.6 , which means they achieved the required level. ${ }^{35}$ All values of average variance extracted (AVE) were above 0.5 , indicating satisfactory construct reliability and adequate convergent validity. ${ }^{36}$ For factor six, despite its AVE value being less than 0.5 , its other indicators were satisfactory-factor loadings of the two items were 0.658 and 0.741 , respectively, and CR value was 0.658 ; hence, it was kept in the M-NHSOPS Scale. The square between the respective constructs was less than the square of AVE for the construct that achieved the discriminant validity of M-NHSOPSC..$^{35}$

In M-NHSOPS, factor one was named 'perceptions of resident safety and related administrative support', which included 10 items (D1/D2/C3/D4/D5/D6/D7/D8/D9/ D10). Its Cronbach's $\alpha$ value was 0.913 , and item loading ranged from 0.569 to 0.808 . It was a combination of three original dimensions 'overall perceptions of resident safety', 'management support for resident safety' and 'organisational learning'. This combination of dimensions is consistent with the composition of factors in the
Norwegian version. ${ }^{15}$ However, there was a minor difference: in M-NHSOPS, item D3 was replaced by C3 in the Norwegian version. The composition of the three dimensions in both studies indicates that there exists homogeneity between 'organisational learning' and 'management support for resident safety' in some cultures. Factor two was named 'handoffs' containing five items (B1/B2/ $\mathrm{B} 3 / \mathrm{B} 6 / \mathrm{B} 10)$. Its Cronbach's $\alpha$ value was 0.851 , and item loading ranged from 0.513 to 0.801 . Items $\mathrm{B} 1 / \mathrm{B} 2 / \mathrm{B} 3 /$ $\mathrm{B} 10$ belong to the original dimension 'handoffs', while B6 'staff tell someone if they see something that might harm a resident' belongs to the original dimension 'feedback and communication about incidents'. This can be viewed and explained such that the staff would closely and actively communicate with each other on any potential safety hazards, for which they consider such in-time communication as essential and valuable. Factor three was named 'teamwork' and contained three items (A1/ A2/A5). Its Cronbach's $\alpha$ value was 0.797 , and item loading ranged from 0.690 to 0.844 . The original dimension 'teamwork' contained all three items above and item A9 'when someone gets really busy in this nursing home, other staff help out'. However, in M-NHSOPS, A9 was deleted since in the context of Chinese cultures assisting colleagues is merely a favour and not an individual's responsibility in terms of workplace regulation or ethics. Moreover, factor five was named 'feedback and communication about incidents' and included two items (B5/ B8). Its Cronbach's $\alpha$ value was 0.851 , and item loading ranged from 0.815 to 0.840 . The original dimension 'feedback and communication about incidents' included four items, which were B5, B8, B4, 'when staff report something that could harm a resident, someone takes care of it', and B6 'staff tell someone if they see something that might harm a resident'. B6 was merged into factor two 'handoffs', while B4 was deleted automatically from the original nine-factor structure. Eventually, factor six was named 'compliance with procedures' and contained two items (A6/A14). Its Cronbach's $\alpha$ value was 0.648 , and item loading ranged from 0.693 to 0.761 . In the original dimension 'compliance with procedures', A4 'staff follow standard procedures to care for residents' was included. The deletion may be due to lack of standard procedures to care for residents in most of the NHs in mainland China as well as lack of national/provincial standard for determining the quality of care in NHs. ${ }^{37}$

In this study, the value of Cronbach's $\alpha$ that is $>0.6$ is considered reliable ${ }^{38}$ Cronbach's $\alpha$ that ranges from 0.7 to 0.8 is deemed to be acceptable and Cronbach's $\alpha$ that is $>0.8$ is considered adequate ${ }^{39}$ The overall Cronbach's $\alpha$ of the scale was 0.883 . It was close to Xiao's study ${ }^{22}$ but lower than Taiwan and China versions. ${ }^{12}$ Cronbach's $\alpha$ value of dimensions of M-NHSOPS ranged from 0.648 to 0.913, illustrating exceptional reliability and satisfactory internal consistency. The recovery rate of the test-retest experiment was $100 \%$, and all values of the total scale and every dimensions were above 0.7 , indicating that the testretest survey has satisfactory performance on validity. ${ }^{40}$ 
M-NHSOPS has five dimensions and 22 items, while Taiwan and China versions has four dimensions with 29 items. ${ }^{12}$ There exist 17 identical items between versions above; however, they have different compositions of dimensions. This result confirms the differences between mainland China and Taiwan, which is mentioned in the introduction. ${ }^{23-25}$ Moreover, Lin's study was applied among 309 staff in 30 long-term care facilities, and the sample size was smaller than that in the present study. Similarly, significant differences were shown between M-NHSOPS and Xiao's ${ }^{22}$ version: (1) 23 items were included in Xiao's result, and 22 items were included in M-NHSOPS; (2) in Xiao's study, it merely has 13 identical items with items included in M-NHSOPS; and (3) there are six dimensions in Xiao's research while five dimensions in M-NHSOPS. Moreover, the compositions of each dimension are entirely different. The differences can be explained by the various inclusions of participants between these two studies: (1) the sample size in Xiao's research was too small and merely included six NHs and 322 respondents; (2) in the pilot study, we found that the employees, such as support staff, securities and canteen staff who do not directly provide care service to the elderly, have insufficient understanding and integration of PSC as they do not participate in daily care routine; (3) the scale contains a large number of items related to the care for the elderly, which makes it difficult for the non-direct care provider to respond; and (4) sampling in Xiao's study showed that medical staff accounted for most significant proportion (professional medical staff was $67.7 \%$, while the nursing assistant was $25.8 \%$ ). However, in Chinese NHs, nursing assistants comprise the largest workforce.$^{41}$ In brief, there still lacks sufficient evidence that the inclusion of all staff types in Chinese $\mathrm{NHs}$ is practical and applicable at present, even though the original developer suggested otherwise. ${ }^{14}$ Regarding this, both the Taiwan and China versions, ${ }^{12}$ and this study merely included direct care providers in organisations. Comparatively, in this study, the inclusion criteria of staff fit the staffing situation in mainland China better, and the sample size is relatively adequate.

Sampling was based on both geographical locations and types of NHs. Researchers attempted to include all possible types of $\mathrm{NHs}$ in each area except in case no exact sort of $\mathrm{NH}$ exists or the only $\mathrm{NH}$ in this type refuses to participate. Thus, a total of $50 \mathrm{NHs}$ were enrolled, of which $17(34.0 \%)$ were type A organisations, 12 (24.0\%) were type B and $21(42.0 \%)$ were type C. It shows that the sampling in this study was evenly distributed and relatively representative. Similarly, as for staffing in NHs, the average number of employees in type A was 30.4 per institution, in type B 26.8 and in type C 17.8. The staffing in private organisations is comparatively insufficient than the other two types of NHs, and this result is consistent with previous literature reviews in the introduction. ${ }^{20}$ However, our study also has some limitations: first, the sample was only from NHs in Southwest China. Further verification of M-NHSOPS on a large sample size elsewhere in China is recommended. Second, this study merely used quantitative research to explore the PSC in $\mathrm{NHs}$ in mainland China. However, qualitative research methods are also recommended to be combined in further research to complete the connotations of PSC in Chinese NHs.

\section{CONCLUSION}

We introduced the NHSOPS Scale into mainland China with a well-applied cultural adaptation process and validated it with a relatively adequate sample size. This study first clarified the inclusion of types of staff in NHs for use of the scale. M-NHSOPS has five dimensions and 22 items, with excellent reliability and validity, making it acceptable and useful. However, further verification among samples in other regions of mainland China is recommended.

\section{Author affiliations}

${ }^{1}$ School of Nursing, West China Hospital, Sichuan University, Chengdu, Sichuan, China

${ }^{2}$ Core Facilities, West China Hospital, Sichuan University, Chengdu, Sichuan, China ${ }^{3}$ Innovation Center of Nursing Research, School of Medicine/West China Hospital, Sichuan University, Chengdu, Sichuan, China

${ }^{4}$ 'Double First-Class' Construction Office, West China Hospital, Sichuan University, Chengdu, Sichuan, China

Acknowledgements This work was supported by Xiuying Hu's graduate students panel, Mingming Zhang's graduate students panel and the participating nursing homes.

Contributors YL, XH and LZ designed the study. XH obtained funding. YL and $\mathrm{LZ}$ collected the data. YL and $\mathrm{YC}$ were involved in data entering and analysing. YL drafted the manuscript. YC, LZ and XH revised the manuscript. All authors were involved in the translation and cultural adapting process and have read and approved the final manuscript. XH and LZ are correspondence authors.

Funding This work was supported by the project of the Chinese Nurse Association grant number ZHKY201406.

Competing interests None declared.

Patient and public involvement statement Patients and/or the public were not involved in the design, conduct, reporting or dissemination plans of this research.

Patient consent for publication Not required.

Ethics approval This study was supported by the institutional review board of West China Hospital, Sichuan University (Chengdu, China), and the approval number is 2017-268. Informed consent was obtained. And data in this study were all anonymous and used exclusively for academic purposes.

Provenance and peer review Not commissioned; externally peer reviewed.

Data availability statement № data are available. No additional data are available.

Supplemental material This content has been supplied by the author(s). It has not been vetted by BMJ Publishing Group Limited (BMJ) and may not have been peer-reviewed. Any opinions or recommendations discussed are solely those of the author(s) and are not endorsed by BMJ. BMJ disclaims all liability and responsibility arising from any reliance placed on the content. Where the content includes any translated material, BMJ does not warrant the accuracy and reliability of the translations (including but not limited to local regulations, clinical guidelines, terminology, drug names and drug dosages), and is not responsible for any error and/or omissions arising from translation and adaptation or otherwise.

Open access This is an open access article distributed in accordance with the Creative Commons Attribution Non Commercial (CC BY-NC 4.0) license, which permits others to distribute, remix, adapt, build upon this work non-commercially, and license their derivative works on different terms, provided the original work is properly cited, appropriate credit is given, any changes made indicated, and the use is non-commercial. See: http://creativecommons.org/licenses/by-nc/4.0/. 
ORCID iD

Yaqin Li http://orcid.org/0000-0003-0024-1210

\section{REFERENCES}

1 Brauner D, Werner RM, Shippee TP, et al. Does nursing home compare reflect patient safety in nursing homes? Health Aff 2018;37:1770-8.

2 Waterson P. Patient safety culture: theory, methods and application. New York: CRC Press, 2018.

3 Farup PG. Are measurements of patient safety culture and adverse events valid and reliable? Results from a cross sectional study. BMC Health Serv Res 2015;15:186.

4 Gartshore E, Waring J, Timmons S. Patient safety culture in care homes for older people: a scoping review. BMC Health Serv Res 2017; $17: 752$

5 Nieva VF, Sorra J. Safety culture assessment: a tool for improving patient safety in healthcare organizations. Qual Saf Health Care 2003;12 Suppl 2:17ii-23.

6 Lee SE, Scott LD, Dahinten VS, et al. Safety culture, patient safety, and quality of care outcomes: a literature review. West J Nurs Res 2019;41:279-304.

7 Deilkås ET, Hofoss D. Psychometric properties of the Norwegian version of the safety attitudes questionnaire (SAQ), generic version (short form 2006). BMC Health Serv Res 2008;8:191.

8 Sørskår LIK, Abrahamsen EB, Olsen E, et al. Psychometric properties of the Norwegian version of the hospital survey on patient safety culture in a prehospital environment. BMC Health Serv Res 2018;18:784.

9 Firstenberg MS, Stawicki SP. Vignettes in patient Safety-Volume 2. Croatia: InTech, 2018.

10 Nie $\mathrm{Y}$, Mao X, Cui $\mathrm{H}$, et al. Hospital survey on patient safety culture in China. BMC Health Serv Res 2013;13:228.

$11 \mathrm{Li} \mathrm{Y,} \mathrm{Zhao} \mathrm{X,} \mathrm{Zhang} \mathrm{X,} \mathrm{et} \mathrm{al.} \mathrm{Validation} \mathrm{study} \mathrm{of} \mathrm{the} \mathrm{safety} \mathrm{attitudes}$ questionnaire (SAQ) in public hospitals of Heilongjiang Province, China. PLoS One 2017;12:e0179486.

12 Lin S-Y, Tseng WT, Hsu M-J, et al. A psychometric evaluation of the Chinese version of the nursing home survey on patient safety culture. $J$ Clin Nurs 2017;26:4664-74.

13 Castle NG, Wagner LM, Perera S, et al. Assessing resident safety culture in nursing homes: using the nursing home survey on resident safety. J Patient Saf 2010;6:59-67.

14 Agency for Healthcare Research and Quality. Nursing home survey toolkit of nursing home survey on patient safety Culture,2012. available. Available: https://www.ahrq.gov/sops/surveys/nursinghome/index.html

15 Cappelen K, Aase K, Storm M, et al. Psychometric properties of the nursing home survey on patient safety culture in Norwegian nursing homes. BMC Health Serv Res 2016;16:446.

16 Teigné D, Mabileau G, Anthoine E, et al. Transcultural adaptation and psychometric study of the French version of the nursing home survey on patient safety culture questionnaire. BMC Health Serv Res 2019;19:490.

17 Zúñiga F, Schwappach D, De Geest S, et al. Psychometric properties of the Swiss version of the nursing home survey on patient safety culture. Saf Sci 2013;55:88-118.

18 Machón M, Vergara I, Silvestre C, et al. [Cross-cultural adaptation into Spanish of the Nursing Home Survey on Patient Safety Culture questionnaire]. Rev Calid Asist 2014;29:99-103.

19 Ministry of Cilvil Affairs of the People's Republic of China. Notice on the registration and Recordation management of elderly care institutions, 2019. Available: http://mzzt.mca.gov.cn/article/zt_zylfw/ zcyjd/dfwj/201908/20190800019094.shtml

20 Zhan HJ, Liu G, Guan X, et al. Recent developments in institutional elder care in China: changing concepts and attitudes. J Aging Soc Policy 2006;18:85-108.

21 Zhang NJ, Guo M, Zheng X. China: awakening giant developing solutions to population aging. Gerontologist 2012;52:589-96.

22 Xiao QP, XL Y, Tong LF. Analysis of reliability and validity of Chinese version of nursing home survey on patient safety culture. Journal of shanghai jiaotong university(medical science) 2016;36:555-64.

23 Wang $\mathrm{H}-\mathrm{H}$, Tsay S-F. Elderly and long-term care trends and policy in Taiwan: challenges and opportunities for health care professionals. Kaohsiung J Med Sci 2012;28:465-9.

24 Zhan HJ, Liu G, Bai H-G. Recent development in Chinese elder homes: a reconciliation of traditional culture. Ageing Int 2005;30:167-87.

25 Li I-C, Yin TJ-C. Care needs of residents in community-based longterm care facilities in Taiwan. J Clin Nurs 2005;14:711-8.

26 Brown JA, Cooper AL, Albrecht MA. Development and content validation of the burden of documentation for nurses and midwives (BurDoNsaM) survey. J Adv Nurs 2020;76:1273-81.

27 Shi J, Mo X, Sun Z. [Content validity index in scale development]. Zhong Nan Da Xue Xue Bao Yi Xue Ban 2012;37:152-5.

28 Song Y, Anderson RA, Corazzini KN, et al. Staff characteristics and care in Chinese nursing homes: a systematic literature review. Int $J$ Nurs Sci 2014:1:423-36.

29 Wang Y, Liu Y, Tian J, et al. Analysis on nursing competence and training needs of dementia caregivers in long-term care institutions. Int J Nurs Sci 2020;7:198-205.

30 Hai-Ping Y, Wei-Ying Z, You-Qing P, et al. Emergency medical staff's perceptions on cultural value difference-based teamwork issues: a phenomenological study in China. J Nurs Manag 2020;28:24-34.

31 Zhong X, Song Y, Dennis C, et al. Patient safety culture in Peking university cancer hospital in China: baseline assessment and comparative analysis for quality improvement. BMC Health Serv Res 2019;19:1008.

32 Chu L-W, Chi I. Nursing homes in China. J Am Med Dir Assoc 2008;9:237-43.

33 Kline RB. Principles and practice of structural equation modeling. New York: The Guilford press, 2015.

34 Stevens J. Applied multivariate statistics for the social sciences. 5th Edition. New York: Routledge, 2009.

35 Ahmad S, Zulkurnain N, Khairushalimi F. Assessing the validity and reliability of a measurement model in structural equation modeling (SEM). BJMCS 2016;15:1-8.

36 Yusoff MSB. Reliability and validity of the adult learning inventory among medical students. Educ Med J 2011;3:e22-31.

37 Zhang Y, S-a I, Thaniwattananon P. Development and evaluation of care quality indicators for nursing homes in China. Songklanagarind $J$ Nurs 2020;40:133-47.

38 Bayati M, Rashidian A, Akbari Sari A, et al. General practitioners' views on key factors affecting their desired income: a principal component analysis approach. Med J Islam Repub Iran 2017;31:236-40.

39 Andresen EM. Criteria for assessing the tools of disability outcomes research. Arch Phys Med Rehabil 2000;81:S15-20.

40 Rifbjerg-Madsen S, Wæhrens EE, Danneskiold-Samsøe B, et al. Psychometric properties of the painDETECT questionnaire in rheumatoid arthritis, psoriatic arthritis and spondyloarthritis: Rasch analysis and test-retest reliability. Health Qual Life Outcomes 2017; $15: 110$

41 Boscart VM, McCleary L, Stolee P, et al. Enhancing nursing home care for seniors: impact of a living classroom on nursing assistant's education. Educ Gerontol 2020;46:461-72. 